\title{
Esterification of Free Fatty Acids with Glycerol within the Biodiesel Production Framework
}

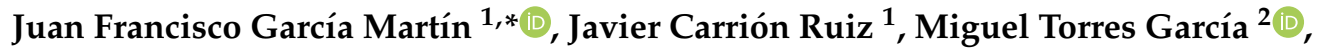 \\ Chao-Hui Feng ${ }^{3}\left(\mathbb{D}\right.$ and Paloma Álvarez Mateos ${ }^{1}$ (D) \\ 1 Departamento de Ingeniería Química, Facultad de Química, Universidad de Sevilla, C/Profesor García \\ González, 1, 41012 Seville, Spain; carriparadas@hotmail.com (J.C.R.); palvarez@us.es (P.Á.M.) \\ 2 Departamento de Ingeniería Energética, E.T.S. de Ingeniería, Universidad de Sevilla, Camino de los \\ Descubrimientos, s/n, 41092 Seville, Spain; migueltorres@us.es \\ 3 RIKEN Centre for Advanced Photonics, RIKEN, 519-1399 Aramaki-Aoba, Aoba-ku, Sendai 980-0845, Japan; \\ chaohui.feng@riken.jp \\ * Correspondence: jfgarmar@us.es; Tel.: +34-954-55-71-83
}

Received: 18 October 2019; Accepted: 5 November 2019; Published: 8 November 2019

\begin{abstract}
Companies in the field of the collection and treatment of waste cooking oils (WCO) for subsequent biodiesel production usually have to cope with high acidity oils, which cannot be directly transformed into fatty acid methyl esters due to soap production. Since glycerine is the main byproduct of biodiesel production, these high acidity oils could be esterified with the glycerine surplus to transform the free fatty acids (FFA) into triglycerides before performing the transesterification. In this work, commercial glycerol was esterified with commercial fatty acids and commercial fatty acid/lampante olive oil mixtures over tin (II) chloride. In the first set of experiments, the esterification of linoleic acid with glycerol excess from 20 to $80 \%$ molar over the stoichiometric was performed. From $20 \%$ glycerol excess, there was no improvement in FFA reduction. Using $20 \%$ glycerol excess, the performance of a biochar obtained from heavy metal-contaminated plant roots was compared to that of $\mathrm{SnCl}_{2}$. Then, the effect of the initial FFA content was assessed using different oleic acid/lampante olive oil mixtures. The results illustrated that glycerolysis was impeded at initial FFA contents lower than 10\%. Finally, the glycerolysis of a WCO with 9.94\% FFA was assayed, without success.
\end{abstract}

Keywords: biodiesel; esterification; free fatty acids; glycerol; waste cooking oil

\section{Introduction}

Vegetable oils undergo numerous physical and chemical alterations during frying due the exposure to high temperatures $\left(160-200^{\circ} \mathrm{C}\right)$ and the presence of oxygen and water. One of these alterations is the increase in acidity in the resulting waste cooking oil (WCO), provoked by the release of free fatty acids (FFA) from the partial hydrolysis of triglycerides.

Waste cooking oils are regarded as an alternative to raw vegetable oils for biodiesel production due to the high cost of the vegetable oils and the threat to food security $[1,2]$. This biodiesel is typically obtained by transesterification, which involves the reaction of triglycerides with a short chain alcohol (generally methanol because of its low cost) in the presence of an alkaline catalyst (mainly sodium hydroxide) to render fatty acid methyl esters (FAME), which are ultimately biodiesel [2].

Companies responsible for the collection, storage, and treatment of WCO usually have to deal with oils with high acidity, which cannot be used as raw material for subsequent biodiesel production $[3,4]$. This is because free fatty acids react with the catalyst of the transesterification reaction, rendering 
soaps (saponification reaction, Equation (1)). The formation of soap significantly reduces the process efficiency, resulting in low biodiesel yields, hence the need to overcome this problem.

$$
\mathrm{R}-\mathrm{COOH}+\mathrm{NaOH} \rightarrow \mathrm{R}-\mathrm{COONa}+\mathrm{H}_{2} \mathrm{O} .
$$

One proposed solution is the previous esterification of the FFA with methanol to obtain FAME [5], i.e., biodiesel, using an acid catalyst (usually sulfuric acid), as shown in Equation (2). This reaction is reversible, so an excess of water can displace the equilibrium towards the formation of FFA [6], thus water should be removed during the process. The most suitable conditions found by several authors for this procedure when treating oils with high acidity were $5 \% \mathrm{H}_{2} \mathrm{SO}_{4}(\mathrm{wt}$.) as catalyst $[4,7,8]$, 15:1 methanol to WCO molar ratio $[4], 160^{\circ} \mathrm{C}[4,8]$ and $2 \mathrm{~h}$ reaction time $[4,8]$. Under these conditions, the acidity of a WCO was reduced from $60.5 \%$ to $1 \%$ FFA. Notwithstanding this, the problem is the further transesterification of the triglycerides, which is not only affected by the presence of water (hydrolysis of triglycerides) but is also inhibited by the presence of high amounts of the product of this reaction, i.e., FAME. As result, the previous esterification drastically reduces the efficiency of the subsequent transesterification, leading to incomplete triglycerides conversion [4].

$$
\mathrm{CH}_{3}-\mathrm{OH}+\mathrm{R}-\mathrm{COOH} \leftrightarrow \mathrm{R}-\mathrm{COO}-\mathrm{CH}_{3}+\mathrm{H}_{2} \mathrm{O}
$$

Another alternative consists of firstly hydrolyzing the triglycerides with an enzyme (lipase) in aqueous medium to obtain FFA (Equation (3)), and then esterifying the resulting FFA with methanol, in the presence of an acid catalyst, into FAME. Lipases from the yeast Candida rugose [4] and from the fungus Rhizopus microsporus [6] have been assayed in the hydrolysis step, none of them achieving high FFA yields.
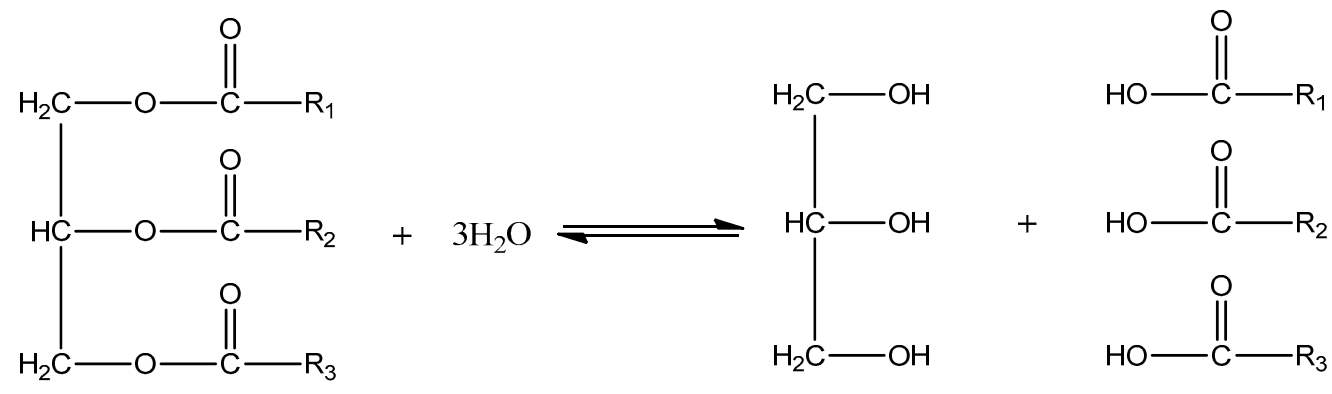

On the other hand, the increasing production of biodiesel has resulted in an oversupply of glycerine as a byproduct [9]. It is estimated that $1 \mathrm{~kg}$ of glycerine (crude glycerol) is produced from every $10 \mathrm{~kg}$ of biodiesel produced by transesterification [10]. Since 42 billion liters of biodiesel will be produced in 2020, according to projections, roughly 4.2 billion liters of glycerine will be available that year [10]. Glycerine from biodiesel production is composed of glycerol (40-70\% wt.), methanol, water, salts, and soap, as well as traces of mono-, di-, and triglycerides that have not entirely reacted. Hence, one last and promising alternative to take advantage of high acidity WCO is to esterify first the FFA with glycerol (glycerolysis) using a Lewis acid catalyst to render triglycerides according to Equation (4), and then perform the transesterification [11]. This alternative is within the framework of circular economy and the biorefinery concept. Nevertheless, a previous purification stage of the glycerine is required to obtain high-purity glycerol for the glycerolysis. At present, the best glycerine purification method is a sequential physicochemical scheme based on acidification driven phase separation with 
phosphoric acid, glycerol extraction with propanol, and subsequent adsorption with activated carbon, the resulting glycerol purity ranging between technical grade [9] and USP [10].

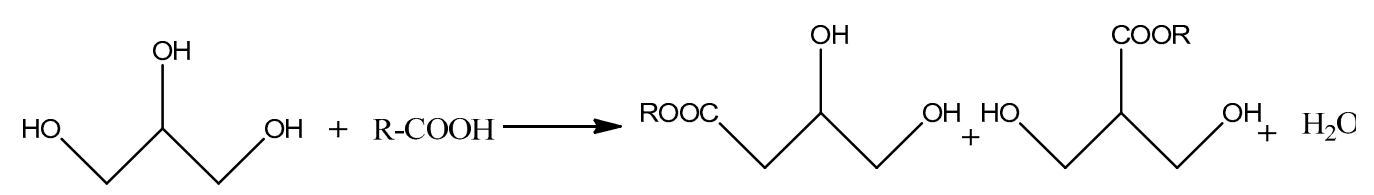

Glycerolysis has been reported to be effective solely when the free fatty acid content is high (5-60\% FFA) [9]. This reaction is carried out in excess of glycerol to shift the equilibrium towards the products. The presence of water is detrimental since the glycerolysis is reversible: water can hydrolyze the formed mono-, di-, and triglycerides, rendering glycerol again [12,13].

Different inorganic catalysts have been assayed for the esterification of $\mathrm{FFA}$ with glycerol, including $\mathrm{AlC}_{2} \cdot 6 \mathrm{H}_{2} \mathrm{O}, \mathrm{Al}_{2} \mathrm{O}_{3}, \mathrm{CdCl}_{2} \cdot 2 \mathrm{H}_{2} \mathrm{O}, \mathrm{FeCl}_{3} \cdot 6 \mathrm{H}_{2} \mathrm{O}, \mathrm{FeO}, \mathrm{HgCl}_{2}, \mathrm{MgCl}_{2} \cdot 6 \mathrm{H}_{2} \mathrm{O}, \mathrm{MgO}, \mathrm{MnCl}_{2} \cdot \mathrm{H}_{2} \mathrm{O}, \mathrm{MnO}_{2}$, $\mathrm{NaOH}, \mathrm{Ni}, \mathrm{NiCl}_{2} \cdot 2 \mathrm{H}_{2} \mathrm{O}, \mathrm{PbCl}_{2}, \mathrm{PbO}, \mathrm{SbCl}_{2}, \mathrm{SnCl}_{2} \cdot 2 \mathrm{H}_{2} \mathrm{O}, \mathrm{SnCl}_{4} \cdot 5 \mathrm{H}_{2} \mathrm{O}, \mathrm{SnO}_{2}, \mathrm{ZnCl}_{2}$, and $\mathrm{ZnO}$ [14]. According to literature, tin (II) chloride dihydrate $\left(\mathrm{SnCl}_{2} \cdot 2 \mathrm{H}_{2} \mathrm{O}\right)$ leads to the highest glycerolysis yields, so this commercial catalyst is the most widely used [13-17]. In this sense, the FFA content of a WCO was reduced from $4.2 \%$ to $1.5 \%$ over $0.1 \% \mathrm{SnCl}_{2} \cdot 2 \mathrm{H}_{2} \mathrm{O}$ (relative to WCO) at $160{ }^{\circ} \mathrm{C}$ in $1 \mathrm{~h}$, using a 0.2 mass ratio of crude glycerol to WCO [13]. Furthermore, the FFA content of soapstocks decreased from 50 to $5 \%$ after $3 \mathrm{~h}$ of glycerolysis at $200{ }^{\circ} \mathrm{C}$ [17].

Temperatures between $120^{\circ} \mathrm{C}$ and $200^{\circ} \mathrm{C}$ are used for glycerolysis, according to literature [15]. In spite of accelerating the reaction rate, the use of high temperatures can lead to the formation of acrolein from glycerol at $167^{\circ} \mathrm{C}$. This gaseous compound (boiling point $=53^{\circ} \mathrm{C}$ ) represents a serious health hazard, so it is preferable to use lower temperatures.

Finally, aiming for a greener process, the inorganic catalyst tin (II) chloride should be replaced with a natural catalyst that has not been submitted to chemical treatment. In this sense, the resulting biochars from the pyrolysis of heavy metal-contaminated roots of the plant Jatropha curcas L. [18] have shown a graphite-like structure and a great performance in the catalysis of similar reactions, such as glycerol esterification with acetic acid or acetic anhydride to obtain oxygenated fuel additives [10], or the esterification of FFA with methanol to render FAME [4].

The aim of this work was to study the reaction of glycerolysis over $\mathrm{SnCl}_{2}$ at a relatively low temperature $\left(160^{\circ} \mathrm{C}\right)$ using commercial glycerol. In the first set of experiments, the ratio of FFA to glycerol was assessed, as well as the performance of a biocatalyst. Secondly, the effect of the initial FFA concentration was studied. Finally, the glycerolysis of a WCO was performed.

\section{Materials and Methods}

\subsection{Esterification Reaction}

Esterification of commercial glycerine (99.5\% glycerol) from Panreac Química S.A.U. (Barcelona, Spain) with FFA was performed in a $250-\mathrm{cm}^{3}$ bath reactor equipped with a temperature controller and a water-cooled condenser, the stirring speed being set at $500 \mathrm{rpm}$. Reaction times between 60 and $120 \mathrm{~min}$ and a temperature of $160{ }^{\circ} \mathrm{C}$ were selected based on the findings of Yeom and Go [13]. As sources of FFA to react with glycerol, commercial linoleic acid (55\% linoleic acid, $35 \%$ oleic acid) from Sigma-Aldrich Química S.L. (Madrid, Spain), commercial oleic acid (65-88\% purity) from Panreac Química S.A.U. (Barcelona, Spain), a lampante virgin oil supplied by Agroalimentaria Virgen del Rocío S.C.A. (Almonte, Spain), and a waste cooking oil supplied by Grupo BIOSEL (Aznalcóllar, Spain) were assayed. Two catalysts were assayed: commercial $\mathrm{SnCl}_{2} \cdot 2 \mathrm{H}_{2} \mathrm{O}$ from Panreac Química S.A.U. (Barcelona, Spain) and a biocatalyst obtained from the pyrolysis of heavy metal-contaminated roots of Jatropha curcas L. at $550{ }^{\circ} \mathrm{C}$ [18]. This biocatalyst has shown a similar performance in esterification reactions to commercial catalyst Amberlyst-15 [4,10]. Its BET surface, average pore diameter, and total 
pore volume were $346 \mathrm{~m}^{2} \cdot \mathrm{g}^{-1}, 4.3 \mathrm{~nm}$, and $0.0446 \mathrm{~cm}^{3} \cdot \mathrm{g}^{-1}$, respectively. The amount of catalyst added to the reaction medium was $1.08 \mathrm{~g}(2.4 \% \mathrm{wt}$. to linoleic acid).

Two sets of experiments were performed. First, the effect of the excess of glycerol (over the stoichiometric) over $\mathrm{SnCl}_{2} \cdot \mathrm{H}_{2} \mathrm{O}$ was assessed and a comparison between the performance of commercial catalyst and that of the biocatalyst was performed under the most favorable conditions (Table 1). For these experiments, linoleic acid was used as the source of FFA and the temperature was fixed at $160^{\circ} \mathrm{C}$.

Table 1. Components and incubation time of the esterification reactions of commercial linoleic acid with different amounts of glycerol at $160^{\circ} \mathrm{C}$.

\begin{tabular}{cccccc}
\hline Run & Linoleic Acid (g) & Glycerol (g) & Glycerol Excess (\%) & Catalyst & t (min) \\
\hline 1 & 45 & 4.48 & 0 & $\mathrm{SnCl}_{2} \cdot 2 \mathrm{H}_{2} \mathrm{O}$ & 80 \\
2 & 45 & 5.37 & 20 & $\mathrm{SnCl}_{2} \cdot 2 \mathrm{H}_{2} \mathrm{O}$ & 80 \\
3 & 45 & 6.27 & 40 & $\mathrm{SnCl}_{2} \cdot 2 \mathrm{H}_{2} \mathrm{O}$ & 80 \\
4 & 45 & 8.06 & 80 & $\mathrm{SnCl}_{2} \cdot 2 \mathrm{H}_{2} \mathrm{O}$ & 80 \\
5 & 45 & 5.37 & 20 & $\mathrm{SnCl}_{2} \cdot 2 \mathrm{H}_{2} \mathrm{O}$ & 120 \\
6 & 45 & 5.37 & 20 & Biocatalyst & 120 \\
\hline
\end{tabular}

In the second set of experiments, different mixtures of commercial oleic acid and the lampante olive oil were used as the source of FFA for the esterification of glycerol over commercial $\mathrm{SnCl}_{2}$ (Table 2). For these experiments, the temperature and reaction time were fixed to $160^{\circ} \mathrm{C}$ and $60 \mathrm{~min}$, respectively.

Table 2. Esterifications of mixtures of commercial oleic acid and lampante olive oil over $\mathrm{SnCl}_{2} \cdot 2 \mathrm{H}_{2} \mathrm{O}$ at $160{ }^{\circ} \mathrm{C}$ for $60 \mathrm{~min}$ (mean $\pm \mathrm{SD}, n=2$ ).

\begin{tabular}{cccc}
\hline Run & Oleic Acid (\%) & Lampante Oil (\%) & FFA (\%) \\
\hline 7 & 100 & 0 & $99.9 \pm 4.5$ \\
8 & 80 & 20 & $79.6 \pm 3.8$ \\
9 & 60 & 40 & $60.0 \pm 2.9$ \\
10 & 40 & 60 & $37.1 \pm 2.1$ \\
11 & 20 & 80 & $20.8 \pm 1.9$ \\
12 & 0 & 100 & $1.3 \pm 0.5$ \\
\hline
\end{tabular}

Finally, the esterification of the FFA of a WCO $(9.94 \pm 0.13 \%$ FFA $)$ with $20 \%$ glycerol excess over $\mathrm{SnCl}_{2} \cdot 2 \mathrm{H}_{2} \mathrm{O}$ at $160^{\circ} \mathrm{C}$ for $60 \mathrm{~min}$ was assayed. All the experiments were performed in duplicate.

\subsection{Analytical Methods}

Free fatty acids in the different sources of FFA were quantified following the UNE-EN 140140 standard, and expressed as oleic acid percentage. Briefly, $20 \mathrm{~g}$ WCO were placed into $250-\mathrm{cm}^{3}$ wide-mouth Erlenmeyer flasks, along with $100 \mathrm{~cm}^{3}$ ethanol:diethyl ether solution $(1: 1 \mathrm{v} / \mathrm{v})$ and a few drops of phenolphthalein, and then neutralized with $0.1 \mathrm{~N} \mathrm{KOH}$, previously standardized with benzoic acid. The titration ended when a reddish-brown color change was observed. Determinations were performed in duplicate.

The percentage of acidity of the oil was calculated according to the following equation:

$$
\operatorname{FFA}(\%)=\frac{\mathrm{V} \times 0.1 \mathrm{~N}(\mathrm{KOH}) \times 0.282}{\mathrm{~m}} \times 100,
$$

where $\mathrm{V}$ is the spent volume of $\mathrm{KOH}$ in $\mathrm{mL}, 0.1 \mathrm{~N}$ stands for the $\mathrm{KOH}$ normality, 0.282 is the equivalent weight of oleic acid in meq, and $m$ is the mass of the source of FFA in $g$.

The glyceride composition of the samples, before and after the esterification reactions, was analyzed by high performance size exclusion chromatography (HPSEC). This technique makes it possible to 
separate the compounds according to their molecular size. The elution order was as follows: polymers of triglycerides (trimers and dimers), triglycerides (TG), diglycerides (DG), monoglycerides (MG), and finally FFA. For their quantification, a liquid chromatograph Hewlett Packard 1050 working with an isocratic flow rate of $0.7 \mathrm{~cm}^{3} \cdot \mathrm{min}^{-1}$ of tetrahydrofuran (THF) was used. The equipment was provided with a manual rheodyne injector with $20 \mu \mathrm{L}$ loop, a column Agilent PL-gel $3 \mu \mathrm{m}$ (size of pore $100 \AA$ ), and it was connected to a refractive index detector Merck L-7490. The sample concentration was $50 \mathrm{mg} \cdot \mathrm{cm}^{-3}$ THF. The data were processed using the 32 Karat program (Beckman Coulter, Inc.). The total time of the chromatographic analysis was $15 \mathrm{~min}$.

\section{Results}

\subsection{Effect of Mass Ratio of Crude Glycerol to FFA}

In the first set of experiments, esterification of glycerine with FFA was performed at $160^{\circ} \mathrm{C}$ for $80 \mathrm{~min}$ using $\mathrm{SnCl}_{2} \cdot 2 \mathrm{H}_{2} \mathrm{O}$ as the catalyst (runs 1 to 4 , Table 1 ). This salt was selected because it is widely used as a catalyst for glycerol esterification $[13,15,16]$. In their study, Yeom and Go reported that the optimum conditions for glycerol esterification were $0.1 \%$ catalyst concentration, 0.2 mass ratio of crude glycerol to waste cooking oil (4.2\% FFA), $160^{\circ} \mathrm{C}$, and $1 \mathrm{~h}$ of reaction time [13]. We selected the same optimal conditions, but extended the reaction time to $80 \mathrm{~min}$ (Table 1). This was because commercial linoleic acid was used as the source of FFA in our study. The content of FFA of this commercial linoleic acid was $94.4 \pm 0.4 \%$, according to our analytical determination (UNE-EN 140140 standard), far higher than that of the waste cooking oil assayed by Yeom and Go [13]. This led us to assess the ratio FFA to glycerol as well.

The results revealed that there was no difference in esterification efficiency for the different assayed excess glycerol amounts (Figure 1), so $20 \%$ excess glycerol was selected for further experiments. This result is similar to that found by other authors in the esterification of soapstock with $50 \%$ FFA at $220^{\circ} \mathrm{C}$ [17]. As can be seen in Figure 1, the reaction mixture took about 20 min to reach the desired temperature, during which glycerol esterification took place to some extent, so the initial FFA content at time zero (beginning of the reaction at $160{ }^{\circ} \mathrm{C}$ ) was lower than the original FFA content of the source of FFA (Figure 1). Obviously, the reaction rates at temperatures lower than $160{ }^{\circ} \mathrm{C}$ (between -20 and $0 \mathrm{~min}$ ) were lower than the reaction rate at $160^{\circ} \mathrm{C}$, as is illustrated in Figure 1.

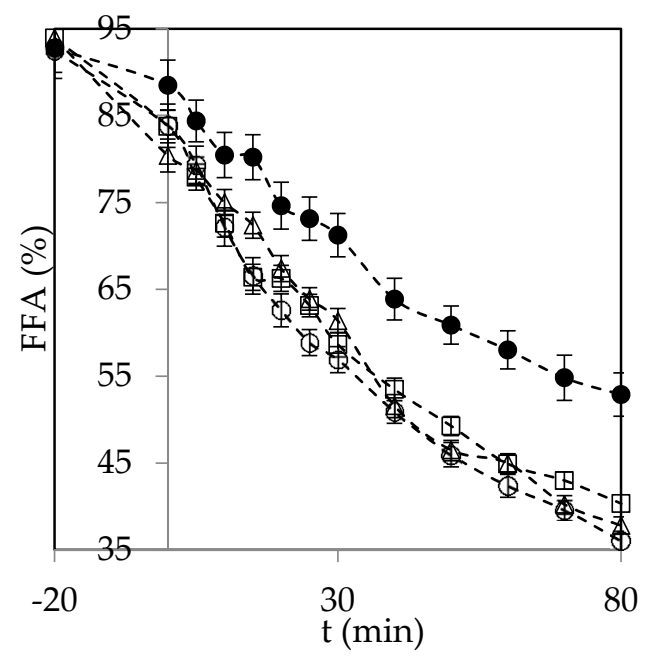

Figure 1. Time course of esterification of linoleic acid with stoichiometric $(\bullet), 20 \%$ excess $(\Delta), 40 \%$ excess ( $\square$ ), and $80 \%$ excess $(\bigcirc)$ glycerol (mean \pm SD, $n=2$ ).

From Figure 1 it cannot be stated that 80 min was enough to reach the completion of the reaction, so a new experiment was performed with $20 \%$ excess glycerol but for 120 min (run 5, Table 1). The results obtained from this experiment revealed that the end of the reaction was close to $80 \mathrm{~min}$ 
(Figure 2). From this time on, the FFA concentration remained roughly constant, being the maximum FFA reduction attained close to $60 \%$.

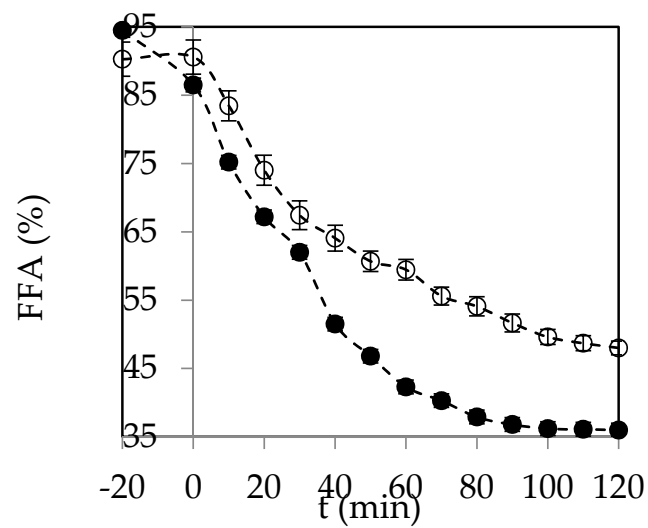

Figure 2. Esterification of linoleic acid with $20 \%$ excess glycerol over $\mathrm{SnCl}_{2} \cdot 2 \mathrm{H}_{2} \mathrm{O}(\bullet)$ or biocatalyst $(\bigcirc)$ at $160{ }^{\circ} \mathrm{C}$ for $120 \mathrm{~min}$ (mean $\pm \mathrm{SD}, n=2$ ).

On the other hand, the performance of the biochar obtained from the pyrolysis at $550{ }^{\circ} \mathrm{C}$ of heavy metal-contaminated roots of Jatropha curcas L. as a catalyst in this reaction was assayed (run 6, Table 1). This biochar was previously demonstrated to achieve an excellent performance in other esterification reactions $[4,10]$. Notwithstanding this, the performance of this biocatalyst was significantly lower than that of the commercial $\mathrm{SnCl}_{2} \cdot 2 \mathrm{H}_{2} \mathrm{O}$ (Figure 2), so it was eliminated from further experiments.

The initial and resulting reaction mixtures of the two experiments with linoleic acid and $20 \%$ excess glycerol at $160{ }^{\circ} \mathrm{C}$ for $120 \mathrm{~min}$ were analyzed by HPSEC (Table 3). The percentages of FFA obtained by HPSEC were in agreement with those obtained by the titration method. The HPSEC results verified that glycerol esterification with FFA occurred, rendering triglycerides (TG), diglycerides (DG), and monoglycerides (MG). The results obtained by HPSEC also illustrated the higher esterification performance of the commercial catalyst, since $\mathrm{SnCl}_{2}$ led to both higher formation of TG and higher conversion of FFA into glyceride compounds (Table 3).

Table 3. Free fatty acid (FFA) conversion yield and triglyceride (TG), diglyceride (DG), monoglyceride (MG) and free fatty acid (FFA) content obtained by high performance size exclusion chromatography (HPSEC) at the beginning and at the end of the esterifications over $\mathrm{SnCl}_{2} \cdot 2 \mathrm{H}_{2} \mathrm{O}$ and the biocatalyst (mean $\pm \mathrm{SD}, n=2$ ).

\begin{tabular}{cccccccc}
\hline Run & Catalyst & t (min) & TG (\%) & DG (\%) & MG (\%) & FFA (\%) & Yield (\%) \\
\hline \multirow{2}{*}{5} & \multirow{2}{*}{$\mathrm{SnCl}_{2} \cdot 2 \mathrm{H}_{2} \mathrm{O}$} & 0 & $2.1 \pm 0.03$ & $3.9 \pm 0.09$ & - & $94.0 \pm 3.9$ & \multirow{2}{*}{$61.1 \pm 1.8$} \\
& & 120 & $15.4 \pm 0.91$ & $37.4 \pm 1.38$ & $10.6 \pm 0.71$ & $36.6 \pm 2.3$ & \\
\hline \multirow{2}{*}{6} & \multirow{2}{*}{ Biocatalyst } & 0 & $2.3 \pm 0.06$ & $4.7 \pm 0.05$ & - & $93.0 \pm 3.6$ & \multirow{2}{*}{$49.3 \pm 0.7$} \\
\hline
\end{tabular}

\subsection{Trials with Different FFA Concentrations}

In this set of experiments, we covered roughly the full range of initial FFA concentrations (Table 2) by adding a commercial fatty acid (to be specific, oleic acid) to a lampante olive oil. An excess of $20 \%$ of commercial glycerol over the stoichiometric one was used. The acidities of the commercial oleic acid and the lampante oil were $99.9 \pm 0.1 \%$ and $1.3 \pm 0.1 \%$, respectively, based on the titration method.

The results revealed that glycerolysis yield decreased when decreasing the initial FFA content. Figure 3 illustrates the change in the content of free fatty acids, this content measured by the titration method. 


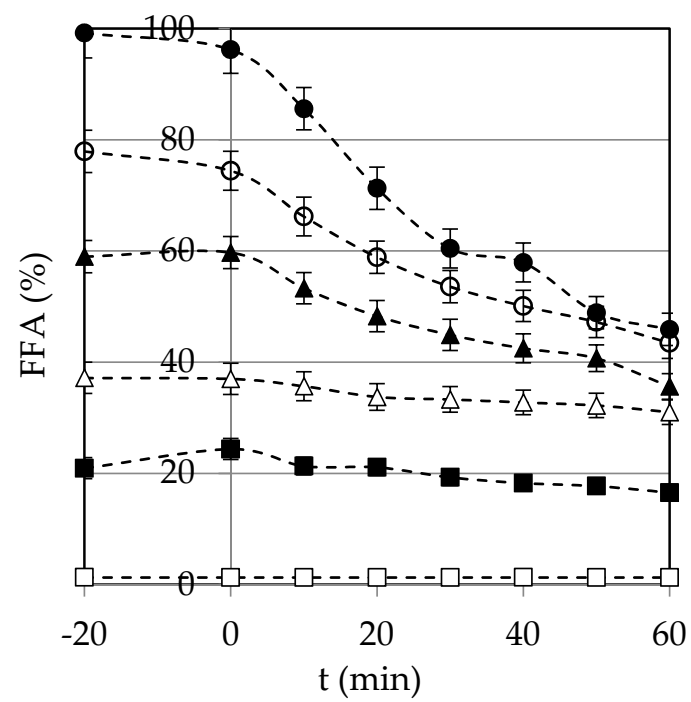

Figure 3. Glycerolysis of mixtures of linoleic acid with $0 \%(\bullet), 20 \%(\bigcirc), 40 \%(\boldsymbol{\Delta}), 60 \%(\Delta), 80 \%(\bullet)$, and $100 \%(\square)$ lampante olive oil (mean \pm SD, $n=2$ ).

The analysis performed by HPSEC provided additional information. When esterifying pure oleic acid (run 7, Table 4), large quantities of mono-, di-, and triglycerides were formed, with DG being the main compound found. One could think that this was be due to steric hindrance to the formation of TG. Notwithstanding this, the TG concentration decreased in the glycerolysis of mixtures of oleic acid and lampante olive (runs 8 to 11, Table 4), with the final concentrations being lower than the initial ones. This can be attributed to triglyceride (and diglyceride) hydrolysis by the water produced in the esterification reaction. As other authors have emphasized, low FFA contents are not suitable for glycerol esterification, at least at the assayed temperature $\left(160^{\circ} \mathrm{C}\right)$, because the water generated in this reaction would shift the equilibrium of transesterification to the reverse reaction [8]. As a result, the esterification with $20 \%$ excess glycerol of lampante olive oil failed (run 12, Table 4), and it only slightly reduced the FFA content of the mixture $20 \%$ oleic acid/ $80 \%$ lampante olive oil (run 11 , Table 4 ).

Table 4. Triglyceride (TG), diglyceride (DG), monoglyceride (MG) and free fatty acid (FFA) content of the mixtures of oleic acid and lampante olive oil obtained by HPSEC at the beginning and at the end of the esterification reactions, and conversion yields (mean $\pm \mathrm{SD}, n=2$ ).

\begin{tabular}{|c|c|c|c|c|c|c|c|c|}
\hline Run & $\begin{array}{c}\text { Oleic } \\
\text { Acid (\%) }\end{array}$ & $\begin{array}{c}\text { Lampante } \\
\text { Oil (\%) }\end{array}$ & $t(\min )$ & TG (\%) & DG (\%) & MG (\%) & FFA (\%) & Yield (\%) \\
\hline \multirow[b]{2}{*}{7} & \multirow[b]{2}{*}{100} & \multirow[b]{2}{*}{0} & 0 & $0.65 \pm 0.01$ & $1.75 \pm 0.06$ & - & $97.57 \pm 3.81$ & \multirow{2}{*}{$60.0 \pm 1.6$} \\
\hline & & & 120 & $10.23 \pm 0.38$ & $37.28 \pm 0.82$ & $13.48 \pm 0.90$ & $39.01 \pm 2.10$ & \\
\hline 8 & 80 & 60 & 120 & $17.26 \pm 0.01$ & $28.33 \pm 0.75$ & $11.51 \pm 0.88$ & $42.90 \pm 2.63$ & $44.6 \pm 0.8$ \\
\hline \multirow[b]{2}{*}{9} & \multirow[b]{2}{*}{60} & \multirow[b]{2}{*}{40} & 0 & $40.67 \pm 0.25$ & $1.71 \pm 0.03$ & - & $57.62 \pm 2.31$ & \multirow[b]{2}{*}{$44.5 \pm 0.8$} \\
\hline & & & 120 & $33.32 \pm 0.15$ & $25.55 \pm 0.38$ & $9.16 \pm 0.75$ & $31.97 \pm 1.80$ & \\
\hline 10 & 40 & 60 & 120 & $52.64 \pm 0.38$ & $13.83 \pm 0.50$ & $4.17 \pm 0.06$ & $29.36 \pm 1.51$ & $23.8 \pm 0.6$ \\
\hline \multirow{2}{*}{11} & \multirow{2}{*}{20} & \multirow{2}{*}{80} & 0 & $80.10 \pm 2.98$ & - & - & $19.90 \pm 0.92$ & \multirow{2}{*}{$23.6 \pm 1.0$} \\
\hline & & & 120 & $64.60 \pm 1.52$ & $13.85 \pm 0.55$ & $6.35 \pm 0.07$ & $15.20 \pm 0.81$ & \\
\hline \multirow{2}{*}{12} & \multirow{2}{*}{0} & \multirow{2}{*}{100} & 0 & $98.69 \pm 3.55$ & - & - & $1.31 \pm 0.03$ & \multirow{2}{*}{$0.0 \pm 0.0$} \\
\hline & & & 120 & $98.66 \pm 3.56$ & - & - & $1.34 \pm 0.03$ & \\
\hline
\end{tabular}

\subsection{Glycerolysis of a Waste Cooking Oil (WCO)}

Finally, the glycerolysis of a WCO over $\mathrm{SnCl}_{2} \cdot 2 \mathrm{H}_{2} \mathrm{O}$ using $20 \%$ excess glycerol was assayed at $160{ }^{\circ} \mathrm{C}$ for $60 \mathrm{~min}$. The FFA content of this WCO was $9.94 \% \pm 0.13 \%$, based on the titration method, and only slightly changed over the course of glycerolysis.

When analyzing the WCO at the beginning and at the end of the glycerolysis by HPSEC, it was found that not only did esterification not occur, but also triglyceride hydrolysis occurred to some 
extent. The HPSEC analysis illustrated that the WCO was mainly composed of glycerides dimers $(7.8 \%)$, TG $(81 \%)$, and FFA (10.4\%), with negligible amounts of DG and MG (Figure $4 a)$. In the HPSEC chromatogram of one of the replica of this experiment (Figure 4b), an increase in the areas in the retention times of DG and MG can be observed. A tentative quantification of these areas gave the following composition: $7.3 \%$ glyceride dimers, $69.4 \%$ TG, $11 \%$ DG, $1.8 \%$ MG, and $10.1 \%$ FFA, which accounts for the hydrolysis of TG into DG and MG, probably due to water contained into the WCO (not measured) and in the catalyst. These results are in contrast to those found by Yeom and Go [13], who stated that the FFA content of a WCO decreased from $4.2 \%$ to $1.5 \%$ in $1 \mathrm{~h}$ when the glycerolysis of this $\mathrm{WCO}$ was performed at $160{ }^{\circ} \mathrm{C}$ for $1 \mathrm{~h}$ over $0.1 \% \mathrm{SnCl}_{2} \cdot 2 \mathrm{H}_{2} \mathrm{O}$ relative to WCO.
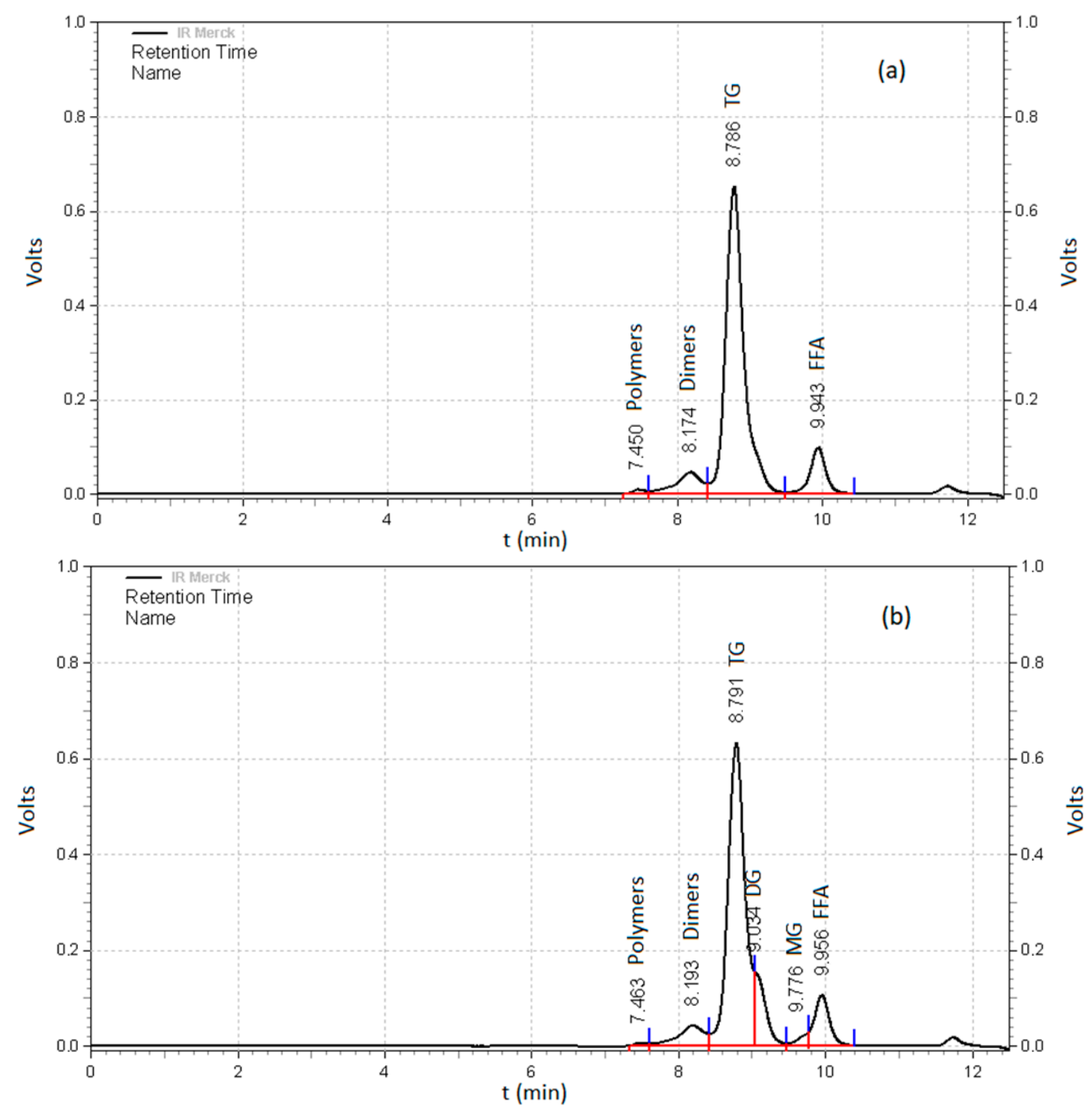

Figure 4. HPSEC chromatograms of the waste cooking oil before (a) and after (b) glycerolysis.

\section{Conclusions}

The results presented in this work show that glycerolysis might be used as a first stage to reduce the FFA content in high-acidic and low-cost feedstocks for biodiesel production. The results illustrated that an excess of glycerol over the stoichiometric is required to increase the FFA conversion, with $20 \%$ being the most suitable glycerol excess. In the esterification of a commercial fatty acid (linoleic acid) with $20 \%$ glycerol excess at $160{ }^{\circ} \mathrm{C}$, it was found that $90 \%$ of the maximum FFA conversion was reached within $60 \mathrm{~min}$ of glycerolysis. The performance of the biochar obtained from heavy metal-contaminated roots of the plant Jatropha curcas L. was lower than that of the commercial catalyst tin (II) chloride dihydrate. 
Thus, the FFA conversion yield was $49.3 \%$ for the biocatalyst, whereas that for $\mathrm{SnCl}_{2} \cdot 2 \mathrm{H}_{2} \mathrm{O}$ was $61.1 \%$. In the set of experiments with mixtures of oleic acid ( $99.9 \%$ FFA) and a lampante olive oil (1.3\% FFA), a competition was observed between glycerolysis (formation of mono-, di- and triglycerides) and hydrolysis (release of FFA from mono-, di-, and triglycerides). As a result, the main reaction product was diglycerides. Due to this competition, glycerolysis is not suitable for oils with relative low acidity. In this sense, the esterification of a waste cooking oil (9.94\% FFA) under the most suitable conditions in this study was unsuccessful.

Author Contributions: Conceptualization, P.Á.M.; methodology, P.Á.M.; formal analysis, J.F.G.M., C.-H.F. and M.T.G.; investigation, J.C.R.; data curation, J.C.R., J.F.G.M. and P.Á.M.; writing—original draft preparation, J.F.G.M.; writing—review and editing, J.F.G.M.; supervision, P.Á.M. and J.F.G.M.; project administration, P.Á.M.; funding acquisition, P.Á.M. and M.T.G.

Funding: This research was funded by European Union under grant LIFE 13-Bioseville ENV/1113.

Acknowledgments: Chao-Hui Feng would like to express her gratitude to University of Seville for the mobility grant (VIPPIT-2018-I.3) awarded under the VI Plan Propio de Investigación y Transferencia of the University of Seville.

Conflicts of Interest: The authors declare no conflict of interest.

\section{References}

1. Sánchez, S.; Cuevas, M.; García-Martín, J.F. Bioethanol production: Corn v/s lignocellulose biomass from olive oil industry and the potential role in ensuring food security. J. Fundam. Renewv. Energy Appl. 2015, 05, 18.

2. García-Martín, J.F.; Barrios, C.C.; Alés-Álvarez, F.J.; Dominguez-Sáez, A.; Alvarez-Mateos, P. Biodiesel production from waste cooking oil in an oscillatory flow reactor. Performance as a fuel on a TDI diesel engine. Renew. Energy. 2018, 125, 546-556. [CrossRef]

3. García Martín, J.F.; del Carmen Barrera, M.L.; Torres García, M.; Zhang, Q.A.; Álvarez Mateos, P. Determination of the acidity of waste cooking oils by near infrared spectroscopy. Processes 2019, 7, 1-7. [CrossRef]

4. Álvarez-Mateos, P.; García-Martín, J.F.; Guerrero-Vacas, F.J.; Naranjo-Calderón, C.; Barrios, C.C.; Pérez-Camino, M.C. Valorization of a high-acidity residual oil generated in the waste cooking oils recycling industries. Grasas y Aceites 2019, 40, 335. [CrossRef]

5. Pereda Marín, J.; Barriga Mateos, F; Álvarez Mateos, P. Aprovechamiento de las oleinas residuales procedentes del proceso de refinado de los aceites vegetales comestibles para la fabricación de biodiesel. Grasas y Aceites 2003, 54, 130-137.

6. Botton, V.; Piovan, L.; Meier, H.F.; Mitchell, D.A.; Cordova, J.; Krieger, N. Optimization of biodiesel synthesis by esterification using a fermented solid produced by Rhizopus microsporus on sugarcane bagasse. Bioprocess Biosyst. Eng. 2018, 41, 573-583. [CrossRef] [PubMed]

7. Marchetti, J.M.; Errazu, A.F. Esterification of free fatty acids using sulfuric acid as catalyst in the presence of triglycerides. Biomass Bioenergy 2008, 32, 892-895. [CrossRef]

8. Chai, M.; Tu, Q.; Lu, M.; Yang, Y.J. Esterification pretreatment of free fatty acid in biodiesel production, from laboratory to industry. Fuel Process. Technol. 2014, 125, 106-113. [CrossRef]

9. Manosak, C.R.; Limpattayanate, S.; Hunsom, M. Sequential-refining of crude glycerol derived from waste used-oil methyl ester plant via a combined process of chemical and adsorption. Fuel Process. Technol. 2011, 92, 92-99. [CrossRef]

10. García-Martín, J.F.; Alés-Álvarez, F.J;; Torres-García, M.; Feng, C.-H.; Álvarez-Mateos, P. Production of Oxygenated Fuel Additives from Residual Glycerine Using Biocatalysts Obtained from Heavy-Metal-Contaminated Jatropha curcas L. Roots. Energies 2019, 12, 740. [CrossRef]

11. Vitiello, R.; Li, C.; Russo, V.; Tesser, R.; Turco, R.; Di Serio, M. Catalysis for esterification reactions: A key step in the biodiesel production from waste oils. Rend. Lincei 2017, 28, 117-123. [CrossRef]

12. Cai, Z.Z.; Wang, Y.; Teng, Y.L.; Chong, K.M.; Wang, J.W.; Zhang, J.W.; Yang, D.-P. A two-step biodiesel production process from waste cooking oil via recycling crude glycerol esterification catalyzed by alkali catalyst. Fuel Process. Technol. 2015, 137, 186-193. [CrossRef] 
13. Yeom, S.H.; Go, Y.W. Optimization of a Novel Two-step Process Comprising Re-esterification and Transesterification in a Single Reactor for Biodiesel Production Using Waste Cooking Oil. Biotechnol. Bioprocess Eng. 2018, 23, 432-441. [CrossRef]

14. Albisu Aguado, M.; Fernández Gil, P. Aceites y grasas industriales. In Bases la Aliment Humana, 2nd ed.; Reverté: Barcelona, Spain, 2008; pp. 103-116.

15. Kombe, G.G.; Temu, A.K.; Rajabu, H.M.; Mrema, G.D.; Kansedo, J.; Lee, K.T. Pre-Treatment of High Free Fatty Acids Oils by Chemical Re-Esterification for Biodiesel Production-A Review. Adv. Chem. Eng. Sci. 2013, 3, 242-247. [CrossRef]

16. Cardoso, A.; Neves, S.; Da Silva, M. Esterification of Oleic Acid for Biodiesel Production Catalyzed by $\mathrm{SnCl}_{2}$ : A Kinetic Investigation. Energies 2008, 1, 79-92. [CrossRef]

17. Felizardo, P.; MacHado, J.; Vergueiro, D.; Correia, M.J.N.; Gomes, J.P.; Bordado, J.M. Study on the glycerolysis reaction of high free fatty acid oils for use as biodiesel feedstock. Fuel Process. Technol. 2011, 92, 1225-1229. [CrossRef]

18. Álvarez-Mateos, P.; Alés-Álvarez, F.-J.; García-Martín, J.F. Phytoremediation of highly contaminated mining soils by Jatropha curcas L. and production of catalytic carbons from the generated biomass. J. Environ. Manag. 2019, 231, 886-895. [CrossRef] [PubMed]

(C) 2019 by the authors. Licensee MDPI, Basel, Switzerland. This article is an open access article distributed under the terms and conditions of the Creative Commons Attribution (CC BY) license (http://creativecommons.org/licenses/by/4.0/). 